\title{
Synthesis, Characterization and Application of Mg/Al Layered Double Hydroxide for the Degradation of Congo Red in Aqueous Solution
}

\author{
Nimibofa Ayawei ${ }^{*}$, Seimokumo Samuel Angaye1, Donbebe Wankasi ${ }^{1,2}$, \\ Ezekiel Dixon Dikio ${ }^{1,2}$ \\ ${ }^{1}$ Department of Chemical Sciences, Niger Delta University, Wilberforce Island, Nigeria \\ ${ }^{2}$ Applied Chemistry and Nanoscience Laboratory, Department of Chemistry, Vaal University of Technology, \\ Vanderbijlpark, South Africa \\ Email: ayawei4acad@gmail.com
}

Received 6 June 2015; accepted 25 July 2015; published 28 July 2015

Copyright (C) 2015 by authors and Scientific Research Publishing Inc.

This work is licensed under the Creative Commons Attribution International License (CC BY).

http://creativecommons.org/licenses/by/4.0/

(c) (i) Open Access

\begin{abstract}
The adsorption properties of layered double hydroxide $\left(\mathrm{Mg} / \mathrm{Al}-\mathrm{CO}_{3}\right)$ for the removal of Congo Red (CR) dye from aqueous solution were studied. The layered double hydroxide was synthesized by co-precipitation method and characterized by X-ray diffraction (XRD), Fourier Transform Infrared spectroscopic (FTIR) and Energy-Dispersive X-ray Spectroscopic (EDX). The effects of various experimental parameters such as contact time, dye concentrations and temperature variation were investigated. The results show that the amount of Congo Red adsorbed increases with increase in temperature but decreases with increase in initial dye concentration and contact time. The data were also fitted to several kinetic models: zero-order kinetic model, first-order kinetic model, second-order kinetic model, pseudo-second-order kinetic model and third-order kinetic model respectively. The adsorption process was best defined by zero-order-kinetic model $\left(R^{2}=1\right)$. Langmuir, Freundich, Temkin and Dubinin-kaganer-Radushkevich (DPK) adsorption isotherm models were applied to analyze adsorption data with Temkin isotherm being the most applicable to the adsorption process. Thermodynamic parameters e.g. $\Delta G^{o}, \Delta S^{o}, \Delta H^{o}$ and $\Delta H_{x}$ of the adsorption process were found to be endothermic, spontaneous and feasible.
\end{abstract}

\section{Keywords}

Congo Red, Layered Double Hydroxides, Kinetic, Dye, Adsorption, Isotherms, Thermodynamics

\footnotetext{
${ }^{*}$ Corresponding author.
}

How to cite this paper: Ayawei, N., Angaye, S.S., Wankasi, D. and Dikio, E.D. (2015) Synthesis, Characterization and Application of $\mathrm{Mg} / \mathrm{Al}$ Layered Double Hydroxide for the Degradation of Congo Red in Aqueous Solution. Open Journal of Physical Chemistry, 5, 56-70. http://dx.doi.org/10.4236/ojpc.2015.53007 


\section{Introduction}

The wastewater disposed by textile industries is causing major hazards to the environment and drinking water due to presence of a large number of contaminants like acids, bases, toxic organic, inorganic, dissolved solids and colour [1]. The presence of such compounds in the industrial wastewater may create serious environmental problems due to toxicity to aquatic life and mutagenicity to humans. In spite of resistance to biodegradation under aerobic conditions, dyes (in particular azo dyes) undergo reductive splitting of the azo bond relatively easily under anaerobic conditions releasing corresponding aromatic amines [2]-[4]. Congo Red is investigated as a mutagen and reproductive effector. It is a skin, eye, and gastrointestinal irritant. It may affect blood factors such as clotting, and induce somnolence and respiratory problems [5]. Therefore, an increased interest has been focused on removing of such dyes from the wastewater. Various physical, chemical and biological methods, including adsorption, biosorption, ozonation, coagulation/flocculation, advanced oxidation, membrane filtration and liquidliquid extraction have been widely used for the treatment of dye-bearing wastewater [6]-[9]. Adsorption is a very effective separation technique and now it is considered to be superior to other techniques for water treatment in terms of initial cost, simplicity of design, ease of operation and insensitive to toxic substances [10]-[13].

Layered double hydroxides also known as hydrotalcite-like compounds or anionic clays, have received much attention in the past decades due to their wide spread applicability. LDHs have positively charged layers of metal hydroxides and the anions and water molecules are located between the layers. The positive charges that are produce from the isomorphous substitution of divalent cations and trivalent cations, are counter balanced by anions located between the layers [14]. LDHs have a general formula of $\left[\mathrm{M}_{1-x}^{2+} \mathrm{M}_{x}^{3+}(\mathrm{OH})_{2}\right]\left[\mathrm{A}_{x / n}^{n-} \cdot m \mathrm{H}_{2} \mathrm{O}\right]$, where $\mathrm{M}^{2+}$ and $\mathrm{M}^{3+}$ are divalent and trivalent metal cations, respectively; $\mathrm{A}$ is the anions, and $x$ is ratio $\mathrm{M}^{3+} /\left(\mathrm{M}^{2+}\right.$ $+\mathrm{M}^{3+}$ ) [15]. The anions between the layers can be polymers, organic dyes, surfactants and organic acids [16]. Layered double hydroxides (LDHs) have in the past three decades received considerable attention due to their flexible interlayer region. A variety of layered materials have been synthesized by different methods and LDHs have widespread applications as catalysts or catalyst precursors [17], adsorbents [18] [19], anionic exchangers [15], in biochemistry [20], polymer additives [21] and as hybrid pigments [22]. This study aims to replicate hydrotalcites which are clays in a laboratory condition for the degradation of Congo Red in aqueous solution.

\section{Experimental}

\subsection{Synthesis of $\mathrm{Mg} / \mathrm{Al}-\mathrm{CO}_{3}$}

Carbonate form of Mg-Al LDH was synthesized by co-precipitation method. A 50 ml aqueous solution containing $0.3 \mathrm{M} \mathrm{Mg}\left(\mathrm{NO}_{3}\right)_{2} \cdot 6 \mathrm{H}_{2} \mathrm{O}$ and $0.1 \mathrm{M} \mathrm{Al}\left(\mathrm{NO}_{3}\right)_{3} \cdot 9 \mathrm{H}_{2} \mathrm{O}$ with $\mathrm{Mg} / \mathrm{Al}$ ratios $4: 1$, was added drop wise into a $50 \mathrm{ml}$ mixed solution of $\mathrm{NaOH}(2 \mathrm{M})+\mathrm{Na}_{2} \mathrm{CO}_{3}(1 \mathrm{M})$ with vigorous stirring and maintaining a $\mathrm{pH}$ of greater than 10 at room temperature. After complete addition which last between 2 hours 30 minutes to 3 hours, the slurry formed was aged at $60^{\circ} \mathrm{C}$ for 18 hours. The products were centrifuged at $5000 \mathrm{rpm}$ for 5 minutes, with distilled water 3 - 4 times and dried by freeze drying.

\subsection{Characterization of Layered Double Hydroxide}

X-ray diffraction (XRD) pattern of the sample was characterized by using a Shimadzu XRD-6000 diffractometer, with Ni-filtered $\mathrm{Cu}-\mathrm{K} \alpha$ radiation $(\lambda=1.54 \AA$ ) at $40 \mathrm{kV}$ and $200 \mathrm{~mA}$. Solid samples were mounted on alumina sample holder and basal spacing (d-spacing) was determined via powder technique. Samples scan were carried out at $10^{\circ}-60^{\circ}, 2 \theta / \mathrm{min}$ at $0.003^{\circ}$ steps.

FTIR spectrum was obtained using a Perkin Elmer 1725X spectrometer where samples will be were finely ground and mixed with $\mathrm{KBr}$ and pressed into a disc. Spectrums of samples were scanned at $2 \mathrm{~cm}^{-1}$ resolution between 400 and $4000 \mathrm{~cm}^{-1}$.

FESEM/EDX was obtained using Carl Zeiss SMT supra 40 VPFESEM Germany and inca penta FET $\times 3$ EDX, Oxford. It was operated at extra high tension (HT) at $5.0 \mathrm{kV}$ and magnification at 20000×. FESEM uses electron to produce images (morphology) of samples and was attached with EDX for qualitative elemental analysis.

\subsection{Preparation of Congo Red Solution}

Congo Red (Figure 1) was supplied by Merck (Mumbai, India). A stock solution of CR dye was prepare 


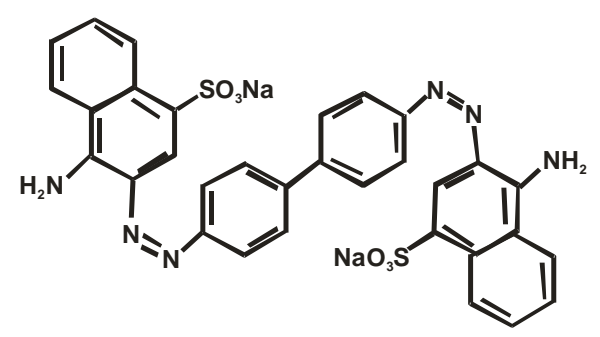

Figure 1. Molecular formula of Congo Red.

(100 mg/L) by dissolving a required amount of dye powder in deionized water. The stock solution was diluted with deionized water to obtain the desired concentrations of 20,30 and $40 \mathrm{mg} / \mathrm{L}$. The supernatants were analyzed using a UV-vis spectrophotometer (Shimadzu, Kyoto, Japan) at wavelength of $497 \mathrm{~nm}$.

\subsection{Adsorption Isotherm Studies}

The quantity of Congo Red removed by the layerd double hydroxide in aqueous solution and the percentage were calculated using Equations (1) and (2) below:

$$
\begin{gathered}
q_{e q l}=\frac{C_{\text {init }}-C_{e q l}}{m} \\
R \%=\frac{C_{\text {init }}-C_{e q l}}{C_{e q l}} \times 100
\end{gathered}
$$

where $C_{\text {init }}$ and $C_{\text {eql }}$ are, respectively, the initial and equilibrium concentrations of dye in solution (mmol/l) and $\mathrm{m}$ is the layered double hydroxide dosage $(\mathrm{g} / \mathrm{l})$.

The data for the uptake of Congo Red at different temperatures has been processed in accordance with the linearised form of the Freundlich and Langmuir isotherm equations.

The Langmuir model linearization (a plot of $1 / q_{\text {eql }}$ vs $1 / C_{e q l}$ ) was expected to give a straight line with intercept of $1 / q_{\max }$ :

$$
\frac{1}{q_{e q l}}=\frac{1}{K_{l} q_{\text {mas }} C_{e q l}}+\frac{1}{q_{e q l}}
$$

The essential characteristics of the Langmuir isotherm were expressed in terms of a dimensionless separation factor or equilibrium parameter $S_{f}$.

$$
S_{f}=\frac{1}{1+a C_{o}}
$$

With $C_{o}$ as initial concentration of Congo Red in solution, the magnitude of the parameter $S_{f}$ provides a measure of the type of adsorption isotherm. If $S_{f}>1.0$, the isotherm is unfavourable; $S_{f}=1.0$ (linear); $0<S_{f}<1.0$ (favourable) and $S_{f}=0$ (irreversible).

For the Freundlich isotherm the In-In version was used:

$$
I n q_{e q l}=\operatorname{InK} K_{f}+\frac{1}{n} \operatorname{In} C_{e q l}
$$

The DKR isotherm is reported to be more general than the Langmuir and Freundlich isotherms. It helps to determine the apparent energy of adsorption. The characteristic porosity of adsorbent toward the adsorbate and does not assume a homogenous surface or constant sorption potential [23].

The Dubinin-Kaganer-Radushkevich (DKR) model has the linear form

$$
\operatorname{Inq}_{e}=\operatorname{In} X_{m}-\beta \varepsilon^{2}
$$

where $X_{m}$ is the maximum sorption capacity, $\beta$ is the activity coefficient related to mean sorption energy, and $\varepsilon$ is the Polanyi potential, which is equal to 


$$
\varepsilon=\operatorname{RTIn}\left(1+\frac{1}{C_{e}}\right)
$$

where $R$ is the gas constant $(\mathrm{kJ} / \mathrm{kmol})$. The slope of the plot of Inq $q_{e}$ versus $\varepsilon^{2}$ gives $\beta\left(\mathrm{mol}^{2} / \mathrm{J}^{2}\right)$ and the intercept yields the sorption capacity, $X_{m}(\mathrm{mg} / \mathrm{g})$. The values of $\beta$ and $X_{m}$, as a function of temperature are listed in Table 1 with their corresponding value of the correlation coefficient, $R^{2}$. It can be observed that the values of $\beta$ increase as temperature increases while the values of $X_{m}$ decrease with increasing temperature.

The values of the adsorption energy, $E$, was obtained from the relationship [24]

$$
E=(2 \beta)^{-1 / 2}
$$

The Temkins isotherm model was also applied to the experimental data, unlike the Langmuir and Freundlich isotherm models, this isotherm takes into account the interactions between adsorbents and dye to be adsorbed and is based on the adsorption that the free energy of adsorption is simply a function of surface coverage [25]. The linear form of the Temkins isotherm model equation is given in (9).

$$
q_{e}=B \ln A+B \ln C_{e}
$$

where $B=\left[R T / b_{T}\right]$ in $(\mathrm{J} / \mathrm{mol})$ corresponding to the heat of adsorption, $R$ is the ideal gas constant, $T(\mathrm{~K})$ is the absolute temperature, $b_{T}$ is the Temkins isotherm constant and $A(\mathrm{~L} / \mathrm{g})$ is the equilibrium binding constant corresponding to the maximum binding energy.

\section{Kinetic Studies}

The experimental data were further subjected to certain kinetic parameters.

Zero-order kinetic model,

$$
q_{t}=q_{o}+K_{o} t
$$

First-Order Kinetic model,

$$
\operatorname{Inq} q_{t}=\operatorname{Inq} q_{o}+K_{1} t
$$

Second-Order Kinetic model,

$$
\frac{I}{q_{t}}=\frac{I}{q_{o}}+K_{2} t
$$

Third-order kinetic model

$$
\frac{1}{q_{t}^{2}}=\frac{1}{q_{o}^{2}}+K_{3} t
$$

Pseudo-second order model

$$
\frac{t}{q_{t}}=\frac{1}{h_{o}}+\frac{1}{q_{e} t}
$$

where $q_{o}(\mathrm{mg} / \mathrm{g})$ and $q_{t}(\mathrm{mg} / \mathrm{g})$ are the adsorbed amounts of CR at equilibrium and time $t(\mathrm{~min}) ; K_{o}, K_{1}, K_{2}$ and $K_{3}$ are the adsorption rate constants for the kinetic models.

\subsection{Thermodynamic Studies}

The thermodynamic parameters such as change in free energy $\Delta G^{o}$, enthalpy change $\Delta H^{0}$ and entropy change $\Delta S^{o}$ were determined by using the following equations:

$$
\begin{gathered}
G^{o}=-R \operatorname{TIn} K_{d} \\
\Delta G^{*}=\Delta H^{*}-T \Delta S^{*}
\end{gathered}
$$

where $K_{d}$ equals the ratio of $C_{\text {solid }}$ and $C_{\text {liquid. }} C_{\text {solid }}$ is the equilibrium concentration of adsorbate on the adsorbent $(\mathrm{mg} / \mathrm{L}), C_{\text {liquid }}$ is the equilibrium concentration of adsorbate in solution $(\mathrm{mg} / \mathrm{L}), T$ is temperature $(K)$ and $R$ is the ideal gas constant $\left(8.314 \mathrm{~J} \cdot \mathrm{mol}^{-1} \cdot \mathrm{K}^{-1}\right)$. 
Table 1. Characteristic parameters of the adsorption isotherm models for Congo Red adsorption by layered double hydroxide.

\begin{tabular}{ccc}
\hline Isotherm model & Isotherm parameter & Results \\
\hline \multirow{2}{*}{ Freundlich } & $1 / n$ & 1.0875 \\
& $K_{F}, \mathrm{mg} / \mathrm{L}$ & 2.2403 \\
Langmuir & $R^{2}$ & 0.9936 \\
\hline \multirow{2}{*}{ Dubinin-Kaganer-Radushkevich } & $R_{L}$ & 0.802 \\
& $R^{2}$ & 0.9925 \\
\hline Temkin & $E, \mathrm{~kJ} / \mathrm{mol}$ & 0.698 \\
& $\beta_{D}, \mathrm{~mol}^{2} / \mathrm{kJ}$ & 1.0263 \\
& $q_{D}, \mathrm{mg} / \mathrm{g}$ & 0.9543 \\
& $R^{2}$ & 0.996 \\
\hline & $A$ & 1.372 \\
& $b$ & $1.36 \times 10^{3}$ \\
& $B$ & 1.6637 \\
\hline
\end{tabular}

The differential isosteric heat of adsorption $\left(\Delta H_{x}\right)$ at constant surface coverage was calculated using the Clausius-Clapeyron equation:

$$
\frac{\mathrm{d} I n\left(C_{e q l}\right)}{\mathrm{d} T}=-\frac{\Delta H_{x}}{R T^{2}}
$$

Integration gives the following equation [18]:

$$
\operatorname{In}\left(C_{\text {eql }}\right)=\frac{\Delta H_{x}}{R} \frac{1}{T}+k
$$

where $K$ is a constant. The differential isosteric heat of adsorption was calculated from the slope of the plot of $\ln \left(C_{e q}\right)$ vs $1 / T$ and was used for an indication of the adsorbent surface heterogeneity.

The linear form of the modified Arrhenius expression was applied to the experimental data to evaluate the activation energy $\left(E_{a}\right)$ and sticking probability $S^{*}$ as shown in Equation (19).

$$
\operatorname{In}(1-\theta)=S^{*}+\frac{E_{a}}{R T}
$$

where $\theta$ is the degree of surface coverage, $T$ is absolute solution temperature and $R$ is gas constant (8.314 $\mathrm{J} / \mathrm{mol}^{-1} \cdot \mathrm{K}^{-1}$.

\section{Results and Discussion}

\subsection{Characterization of LDH}

1) SEM

Figure 2 clearly show the pre \& post adsorption SEM images. The SEM image of post adsorption shows coverage of available pores in relation to pre-adsorption image.

2) XRD

The typical XRD pattern (Figure 3) shows a lamellar structure of LDH material. Peaks at 8.6, 23.4 and 34.6 correspond to d-spacing at $1.027 \mathrm{~nm}, 0.3797 \mathrm{~nm}$ and $0.259 \mathrm{~nm}$ respectively. This is consistent with layered materials.

3) FT-IR

The pre and post adsorption FT-IR spectra as shown in Figure 4 resemble those of other hydrotalcite-like phases. The pre-adsorption (a) band at $3408 \mathrm{~cm}^{-1}$ could be attributed to the stretching vibration of hydroxyl 


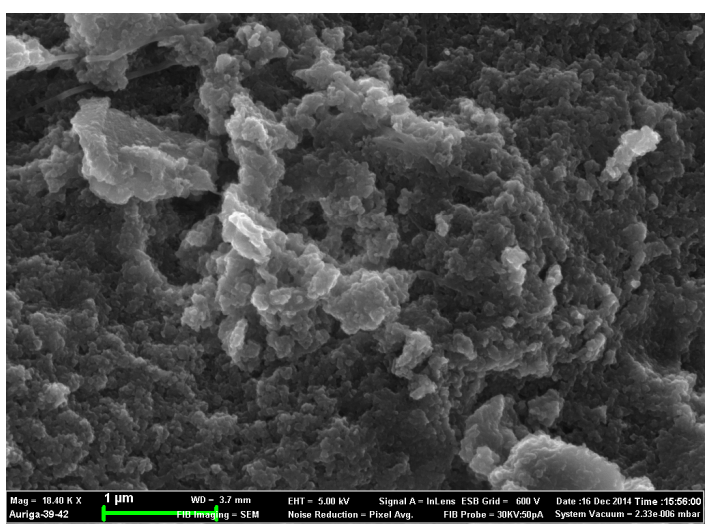

(a)

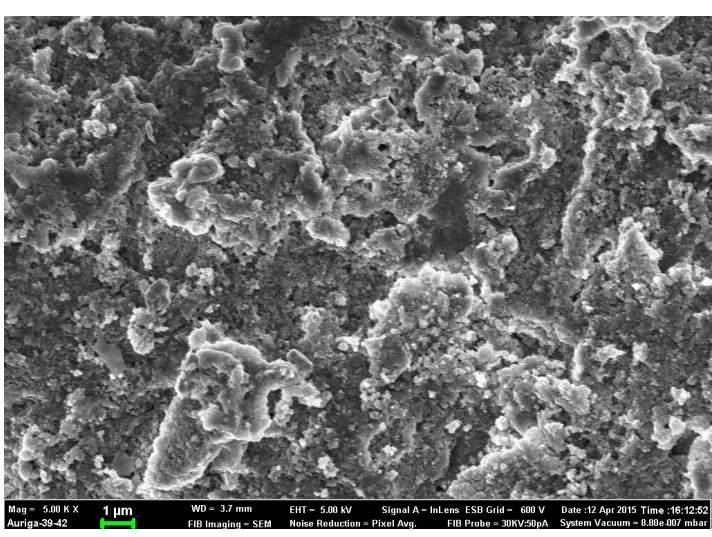

(b)

Figure 2. Scanning Electron Microscope (SEM) micrograph of $\mathrm{Mg} / \mathrm{Al}-\mathrm{CO}_{3}$ before (a) and after (b) adsorption studies.

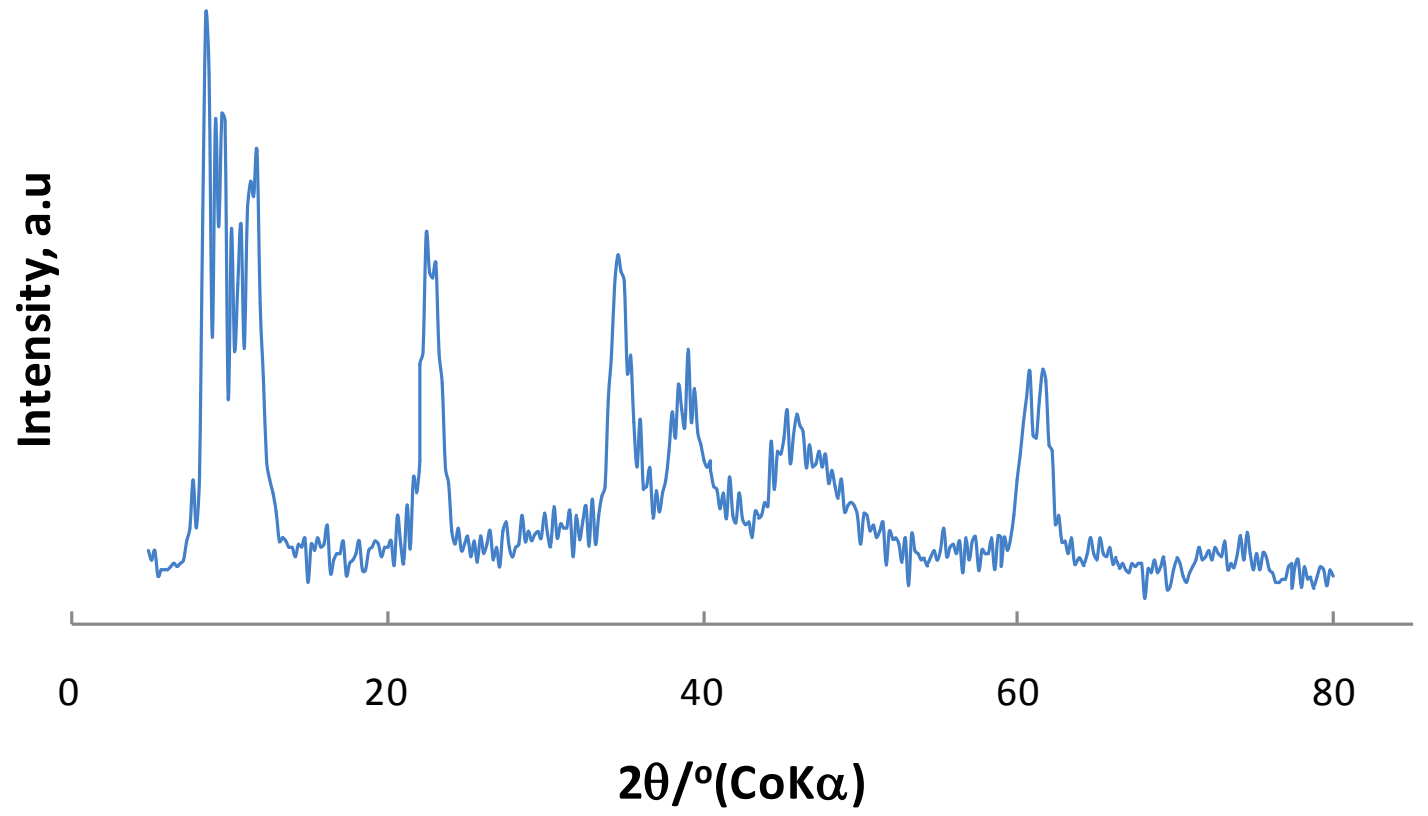

Figure 3. $\mathrm{Mg} / \mathrm{Al}-\mathrm{CO}_{3} \mathrm{X}$-ray powder diffraction.

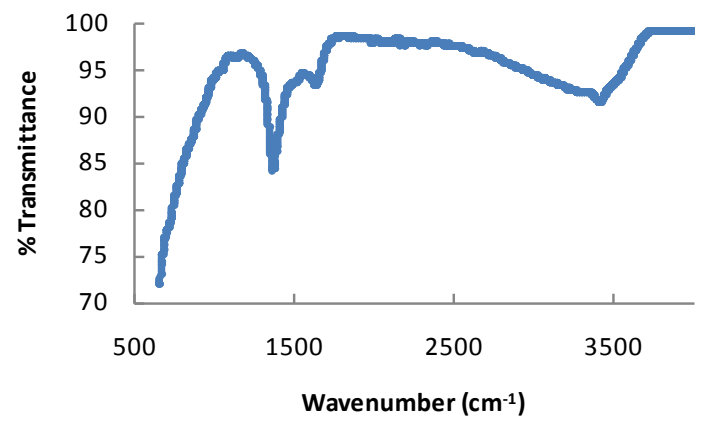

(a)

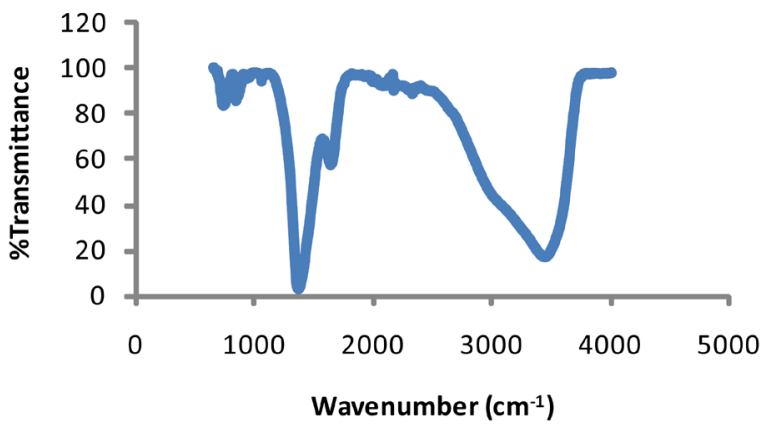

(b)

Figure 4. $\mathrm{Mg} / \mathrm{Al}-\mathrm{CO}_{3}$ Fourier transform infrared spectroscopy, before (a) and after (b) adsorption studies.

group. The low intensity band at $1632 \mathrm{~cm}^{-1}$ is assigned to bending vibration of strongly adsorbed water (solvation water for compensating anion vibration). The band at $1363 \mathrm{~cm}^{-1}$ is assigned to carbonate vibration $\left(\mathrm{CO}_{3}^{2-}\right)$, 
the bands at 672 is due to $\mathrm{M}-\mathrm{O}$ vibration. While the shrinking of the post-adsorption spectra as shown in (b), is attributed to the aromatic ring about $1015 \mathrm{~cm}^{-1}$, the band between $1100 \mathrm{~cm}^{-1}-1200 \mathrm{~cm}^{-1}$ is due to phosphate stressing and the out-of-plane wagging at $650 \mathrm{~cm}^{-1}-900 \mathrm{~cm}^{-1}$ are characteristic of $1^{\circ}$ amines. The change in the FTIR spectra confirms the formation of complex between the functional groups present in the adsorbent and Congo Red [26] [27].

\subsection{Effect of Concentration}

Removal efficiency of Congo Red by adsorbents is illustrated in Figure 5. It shows that removal efficiency decreased with increasing of initial concentration (47.5\%, $46.7 \%$ and $43 \%$ ) respectively, this is probably due to rapid adsorption at all available site and relatively small amount of adsorbent that was used, an increase in the amount of adsorbent may therefore reverse adsorption trend.

\subsection{Isotherm Analysis}

To investigate an interaction of adsorbate molecules and adsorbent surface, four well-known models, the Langmuir, Freundlich, Dubinin-Kaganer-Radushkevic and Temkin isotherms, were selected to explicate LDH interaction in this study.

The Langmuir plot in Figure 6 fitted the experimental data with $R^{2}=0.9925$ and therefore, confirm monolayer coverage. The favourability or otherwise of a Langmuir type isotherm is determined by a dimensionless constant separation factor $\left(R_{L}\right)$, given by Equation (4). The calculated value of $R_{L}$ from Figure 6 is 0.802, which is within the range of $0-1$, thus confirms the favourable uptake of the Congo Red by the LDH. The degree of favourability is generally related to the irreversibility of the system, giving a qualitative assessment of the layered double hydroxide interactions.

$K_{f}$ is a constant describing the adsorption capacity $(\mathrm{mg} / \mathrm{L})$ and $n$ is an empirical parameter related to the adsorption intensity, the plot of $\ln q_{e}$ against $\ln C_{e}$ is shown in Figure 7 gives 2.2403 and 0.92 as values for $K_{F}$ and $n$ respectively.

The values of $k_{F}$ and $n$ determine the steepness and curvature of the isotherm. The Freundlich equation frequently gives $n$ adequate description of adsorption data over a restricted range of concentration, even though it is not based on any theoretical background. Apart from a homogeneous surface, the Freundlich equation is also suitable for a highly heterogeneous surface and an adsorption isotherm lacking a plateau, indicating a multilayer adsorption [28]. The values of $1 / n$, less than unity is an indication that significant adsorption takes place at low concentration but the increase in the amount adsorbed with concentration becomes less significant at higher concentration and vice versa [29]. The magnitude of $K_{F}$ and $n$ shows easy separation of Congo Red dye from wastewater and high adsorption capacity.

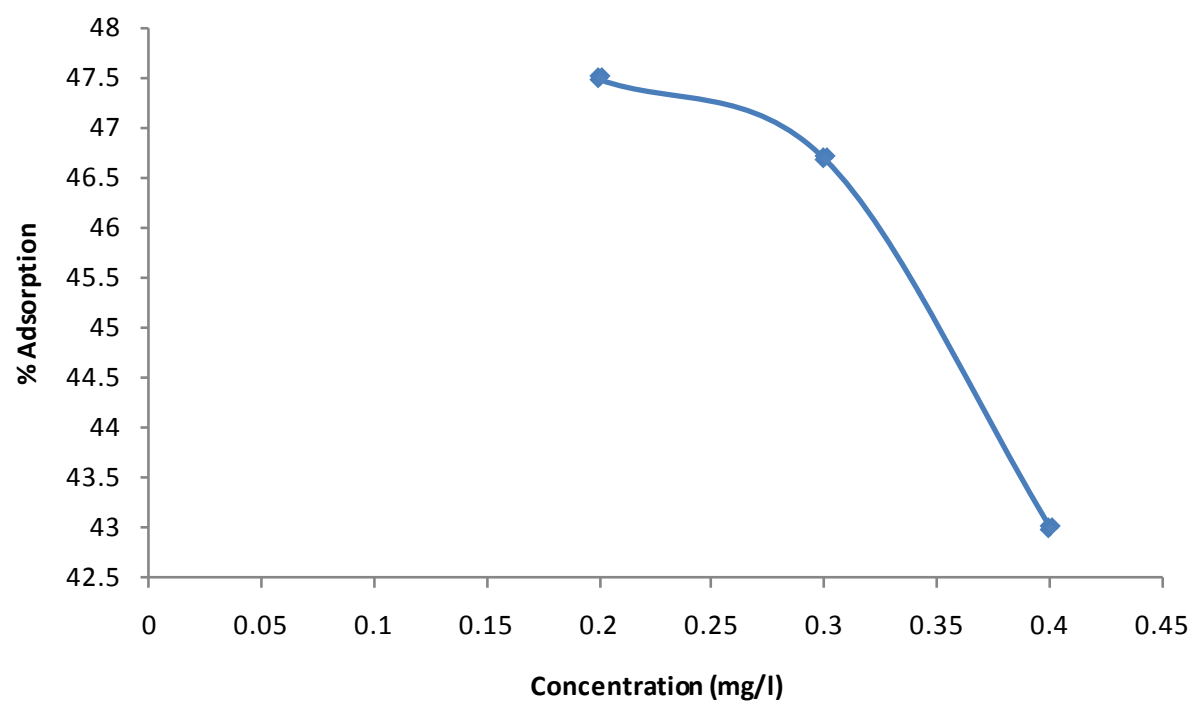

Figure 5. Effect of concentration on adsorption of Congo Red onto layered double hydroxide. 


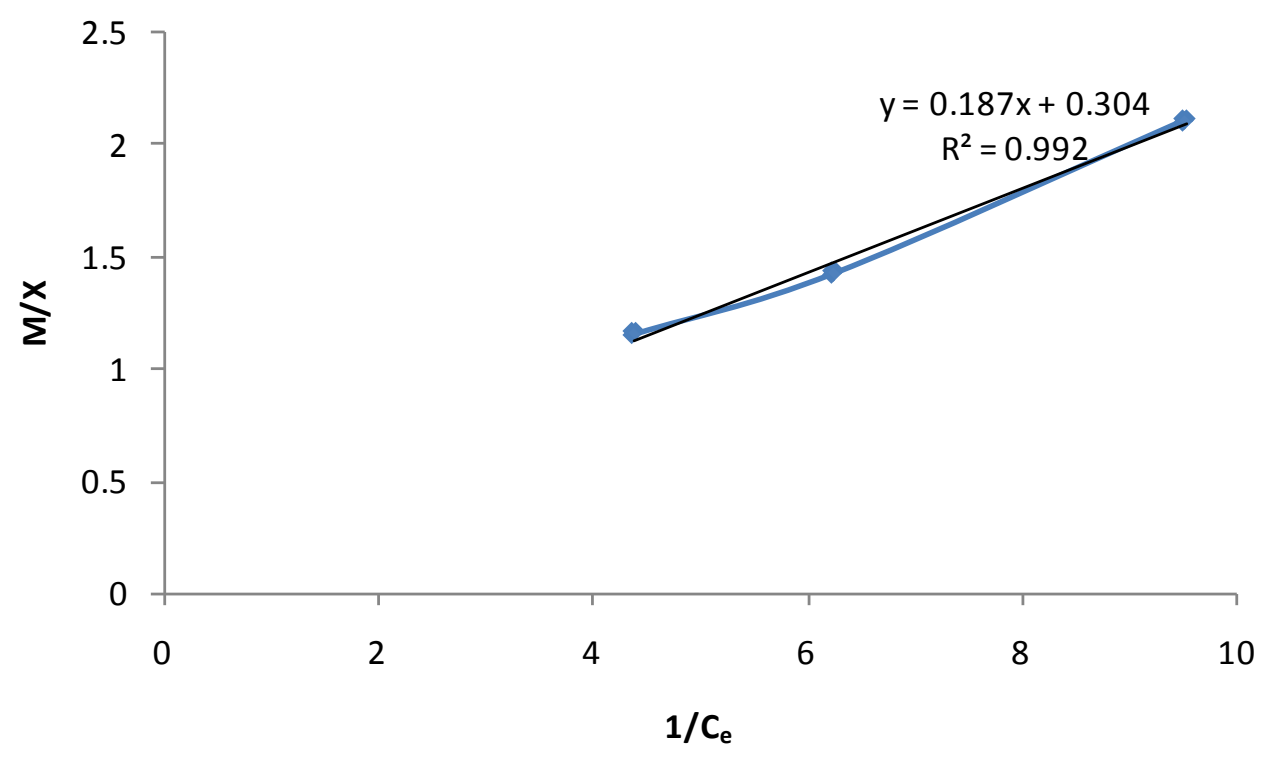

Figure 6. Langmuir isotherm plot for adsorption of Congo Red onto layered double hydroxide.

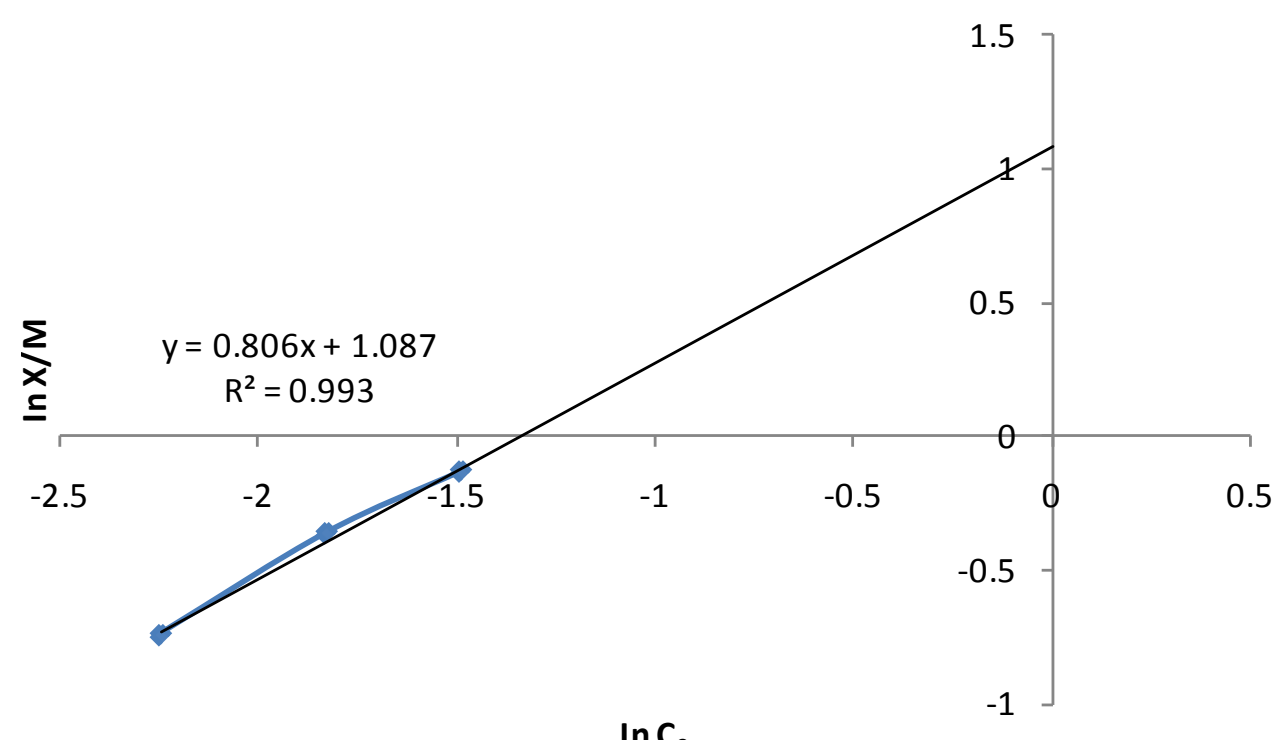

Figure 7. Freundlich isotherm plot for adsorption of Congo Red onto layered double hydroxide.

The fraction of the layered double hydroxide surface covered by the Congo Red is given as 0.47 (Table 1 ). This value indicates that $47 \%$ of the pore spaces of the layered double hydroxide surface were covered by the Congo Red which means less than average degree of adsorption.

The plots of $I n q_{e}$ against $\varepsilon^{2}$ as shown in Figure 8 yielded straight lines and indicates a good fit of the isotherm to the experimental data. The values of linear regression $R^{2}, q_{D}, B_{D}$ and apparent energy $E$ are calculated from the intercepts slopes of the plots respectively are shown on Table 1 and Equation (8). From the linear plot of DRK model, $q_{D}$ was determined to $0.9543 \mathrm{mg} / \mathrm{g}$, the mean energy, $E=0.698 \mathrm{~kJ} / \mathrm{mol}$ indicating a physiosorption process and the $R^{2}=0.996$.

Temkin adsorption isotherm model is usually chosen to evaluate the adsorption potentials of an adsorbent for the adsorbate from an experimental data. This model gives the mechanism and adsorption capacity of an adsorbate in a sorption process. From the Temkin plot shown in Figure 9, the following values were estimated:

$A=1.372 \mathrm{~L} / \mathrm{g}, B=1.6637 \mathrm{~J} / \mathrm{mol}$ which is an indication of the heat of sorption, indicating a physical adsorption process and the $R^{2}=1$. 


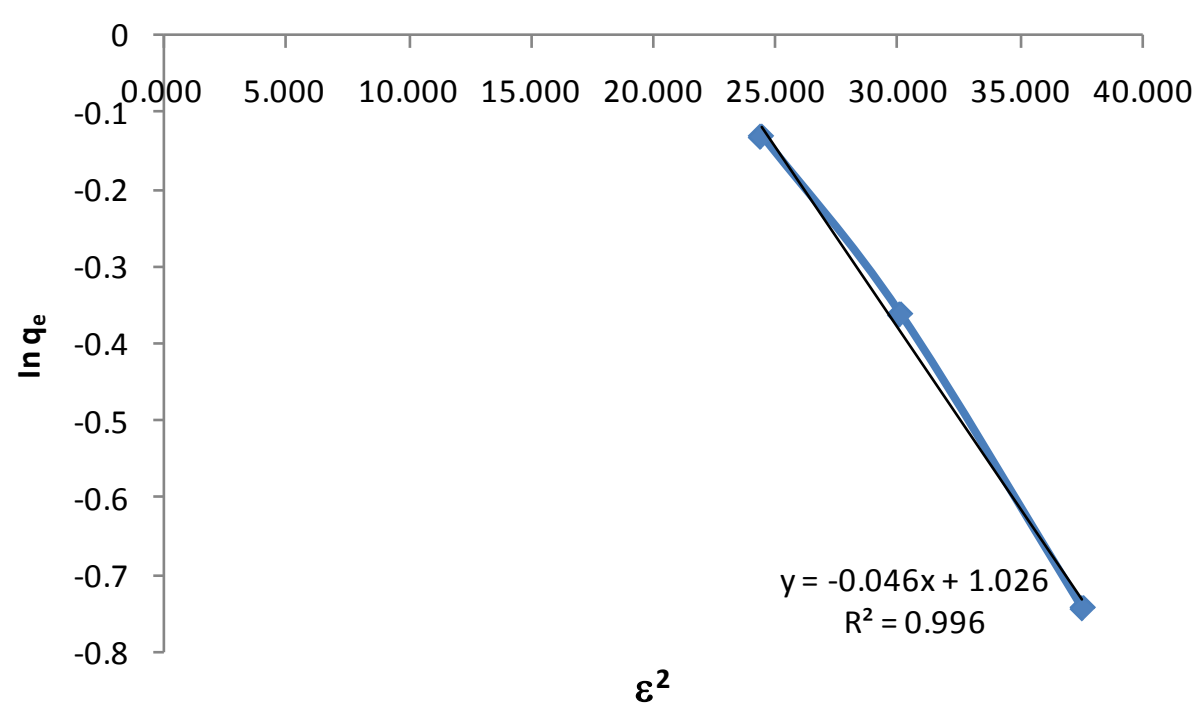

Figure 8. Dubinin-Kaganer-Radushkevic (DKR) isotherm plot for adsorption of Congo Red onto layered double hydroxide.

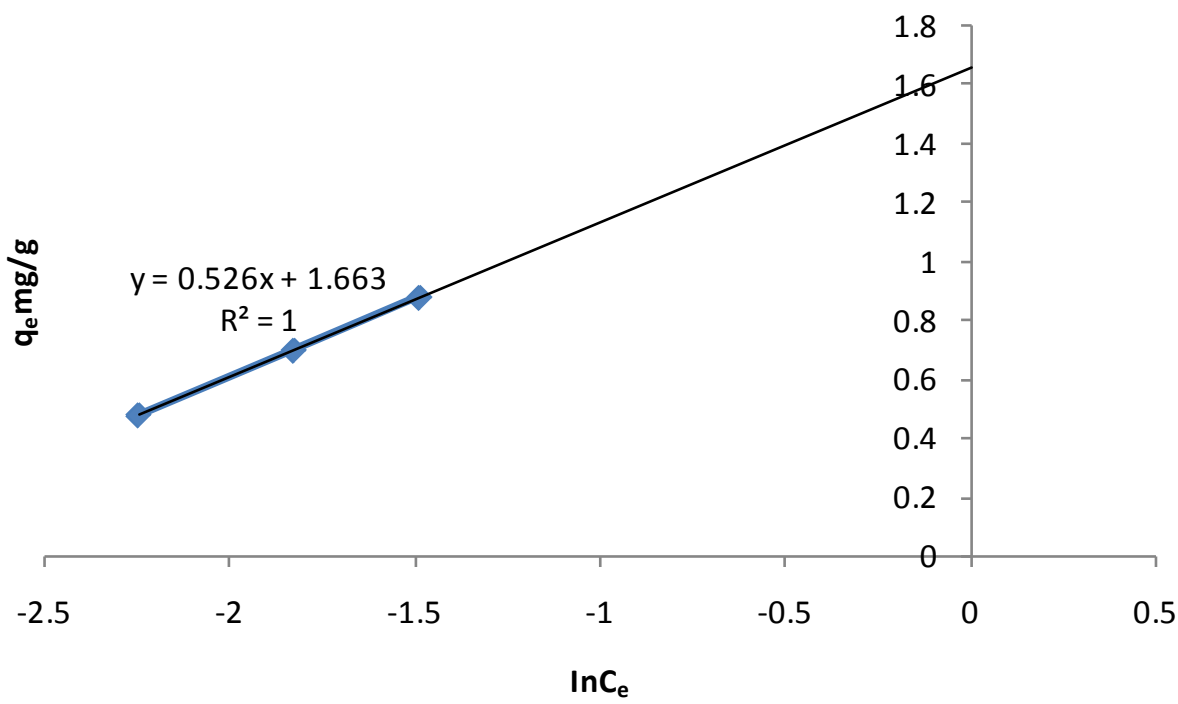

Figure 9. Temkin isotherm model plot for adsorption of Congo Red onto layered double hydroxide.

\subsection{Effect of Temperature}

As shown in Figure 10 adsorption was lowest at $313 \mathrm{~K}$ (52\%), and increased slightly to $333 \mathrm{~K}$ (55\%) and $353 \mathrm{~K}$ (56\%). This means that adsorption capacity increase with higher temperature.

The values of the enthalpy change $\left(\Delta H^{\circ}\right)$ and entropy change $\Delta S^{\circ}$ were calculated from Equation (10) to be $3.67 \mathrm{~kJ} / \mathrm{mol}$ and $12.5 \mathrm{~J} / \mathrm{mol} \cdot \mathrm{K}$ respectively, as shown in Figure 11 . A positive $\Delta H^{\circ}$ suggests that sorption proceeded favourably at a higher temperature and the sorption mechanism was endothermic. A positive value of $\Delta S^{o}(12.5 \mathrm{~J} / \mathrm{mol} \cdot \mathrm{K})$ reflects the affinity of the adsorbent towards the adsorbate species. In addition, positive value of $\Delta S^{o}$ suggests increased randomness at the solid/solution interface with some structural changes in the adsorbate and the adsorbent. The adsorbed solvent molecules, which are displaced by the adsorbate species, gain more translational entropy than is lost by the adsorbate ions/molecules, thus allowing for the prevalence of randomness in the system. The positive $\Delta S^{o}$ value also corresponds to an increase in the degree of freedom of the adsorbed species.

Isosteric heat of adsorption $\Delta H_{x}$ is one of the basic requirements for the characterization and optimization of 
an adsorption process and is a critical design variable in estimating the performance of an adsorptive separation process. It also gives some indication about the surface energetic heterogeneity. Knowledge of the heats of sorption is very important for equipment and process design. A plot of $\mathrm{InC}_{e}$ against 1/T in Figure 12 gives a slope equal to $\Delta H_{x}$. The value of $\Delta H_{x}$ derived from Equation (11) was $40.03 \mathrm{~kJ} / \mathrm{mol}$ which indicates that adsorption mechanism was physical adsorption and in an heterogeneous surface.

The activation energy $E_{a}$ and the sticking probability $S^{*}$ were calculated from Equation (12). The values shown in Table 2 for $E_{a}$ and $S^{*}$ are $-10.13 \mathrm{~kJ} / \mathrm{mol}$ and 0.47 respectively, extrapolated from the plot in Figure 13. The value of activation energy shows that the sorption process was a physical one less than $4.2 \mathrm{~kJ} / \mathrm{mol}$.

\subsection{Effect of Time}

The adsorption kinetic study is important in predicting the mechanisms (chemical reaction or mass-transport process) that control the rate of the pollutant removal and retention time of adsorbed species at the solid-liquid interface [28] [29]. That information is important in the design of appropriate sorption treatment plants.

The effect of contact time of the phases on removal of Congo Red by the Layered double hydroxide from solutions of initial concentration equal to $400 \mathrm{mg} \mathrm{CR} / \mathrm{L}$ at three different times (10, 20 and 30 minutes) is presented in Figure 14.

The result shows that adsorption was highest at 10 minutes, thereafter, a gradual decrease occurred $(10=$ $56.6 \%, 20=55 \%$ and $30=53 \%$ ).

The experimental data were fitted into different kinetic models as shown in Figures 15-18 including zeroorder-kinetic model, second-order-kinetic model, pseudo-second-order-kinetic model and third-order-kinetic model to ascertain the suitability of the models [30]. The correlation coefficient values of 1, 0.9995, 0.9996 and 0.999 respectively confirming the applicability of all the studied models.

\section{Conclusion}

Layered double hydroxide $\left(\mathrm{Mg} / \mathrm{Al}-\mathrm{CO}_{3}\right)$ was successfully synthesized and characterized for the adsorption of

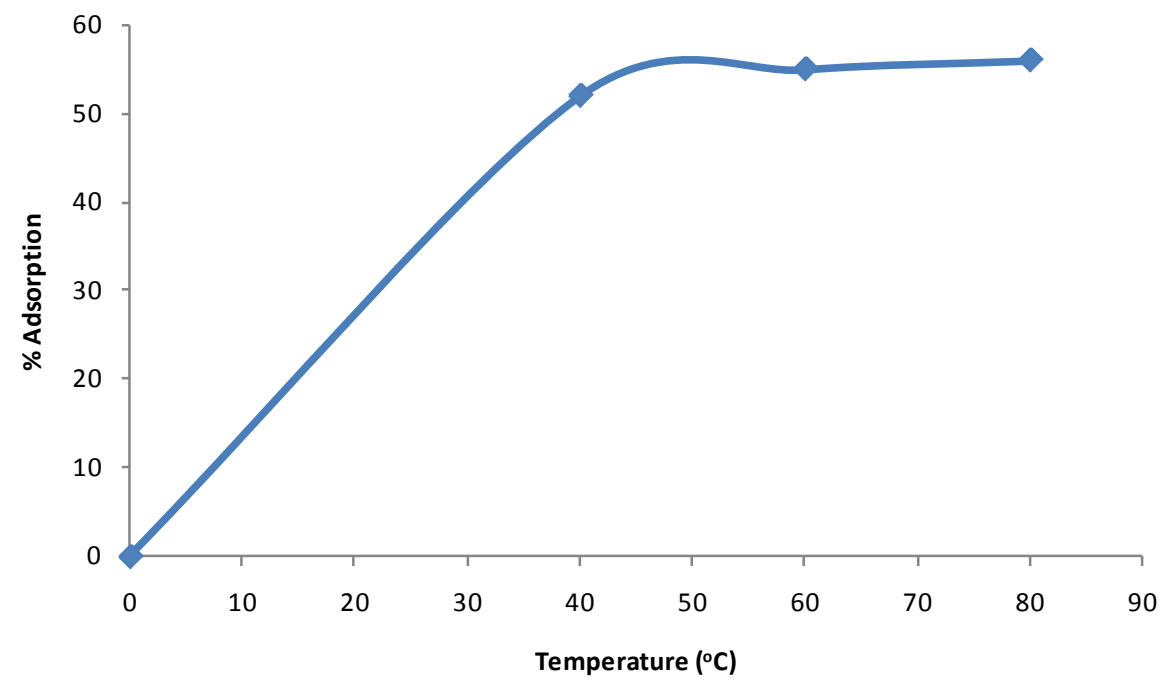

Figure 10. Effect of temperature on adsorption of Congo Red onto layered double hydroxide.

Table 2. Thermodynamic parameters of the adsorption of Congo Red onto layered double hydroxide.

\begin{tabular}{rccccc}
\hline $\boldsymbol{T}, \boldsymbol{K}$ & $\boldsymbol{\Delta} \boldsymbol{G}^{\boldsymbol{o}}, \mathbf{k J} / \mathbf{m o l}$ & $\boldsymbol{\Delta} \boldsymbol{H}^{\boldsymbol{o}}, \mathbf{k J} / \mathbf{m o l}$ & $\boldsymbol{\Delta} \boldsymbol{S}^{\boldsymbol{o}}, \mathbf{J} / \mathbf{m o l} \cdot \mathbf{K}$ & $\boldsymbol{E}_{\boldsymbol{a}}, \mathbf{\mathrm { kJ }} / \mathbf{m o l}$ & $\Delta \boldsymbol{H}_{\boldsymbol{x}}, \mathbf{k J} / \mathbf{m o l}$ \\
\hline 313 & -0.208 & & & & \\
333 & -0.550 & 3.67 & 12.5 & -10.13 & 40.03 \\
353 & -0.707 & & & & \\
\hline
\end{tabular}




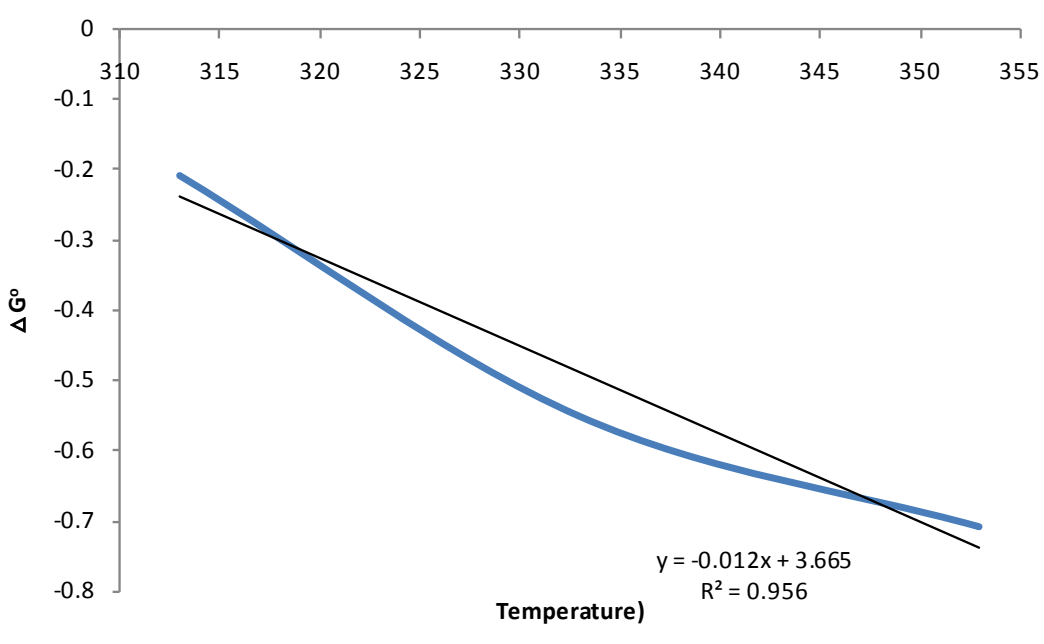

Figure 11. Plot of $\Delta G^{0}$ vs. temperature for the adsorption of Congo Red onto layered double hydroxide.

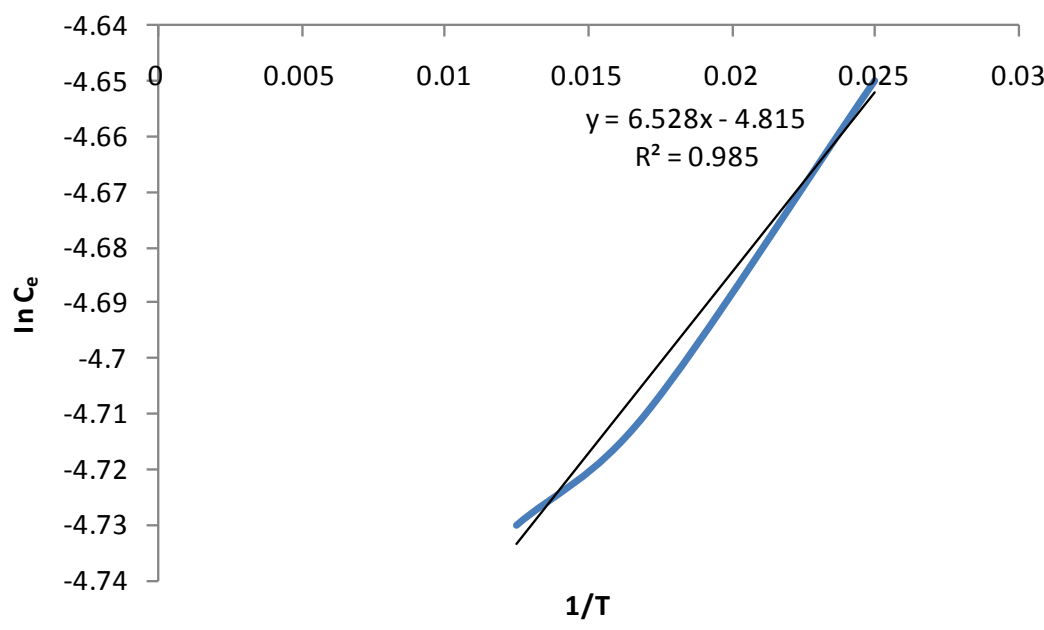

Figure 12. Plot of $\operatorname{In} C_{e}$ vs. $1 / T$ for the adsorption of Congo Red onto layered double hydroxide.

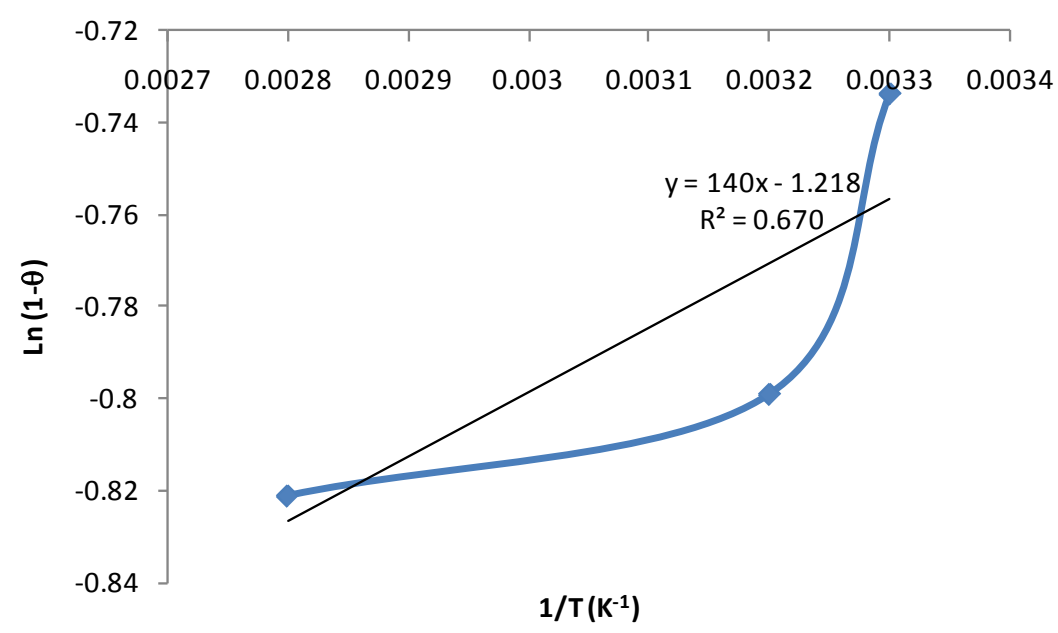

Figure 13. Plot of $\operatorname{Ln}(1-\theta)$ vs. $1 / T\left(\mathrm{~K}^{-1}\right)$ for the adsorption of Congo Red onto layered double hydroxide. 


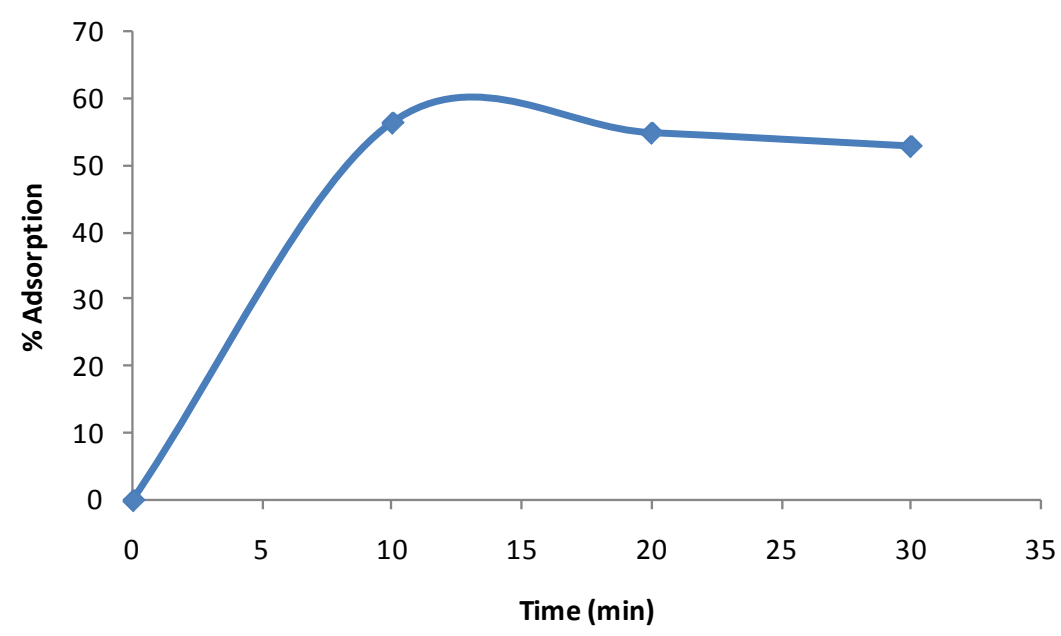

Figure 14. Effect of contact time on adsorption of Congo Red onto layered double hydroxide.

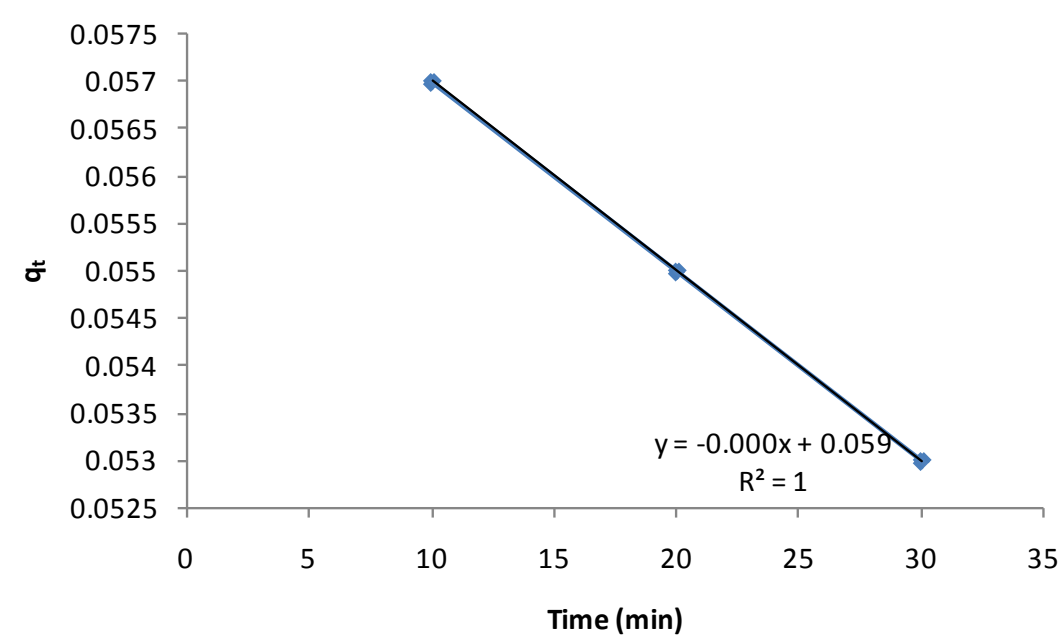

Figure 15. Plot of $q_{t}$ vs. $t$ for the adsorption of Congo Red onto layered double hydroxide.

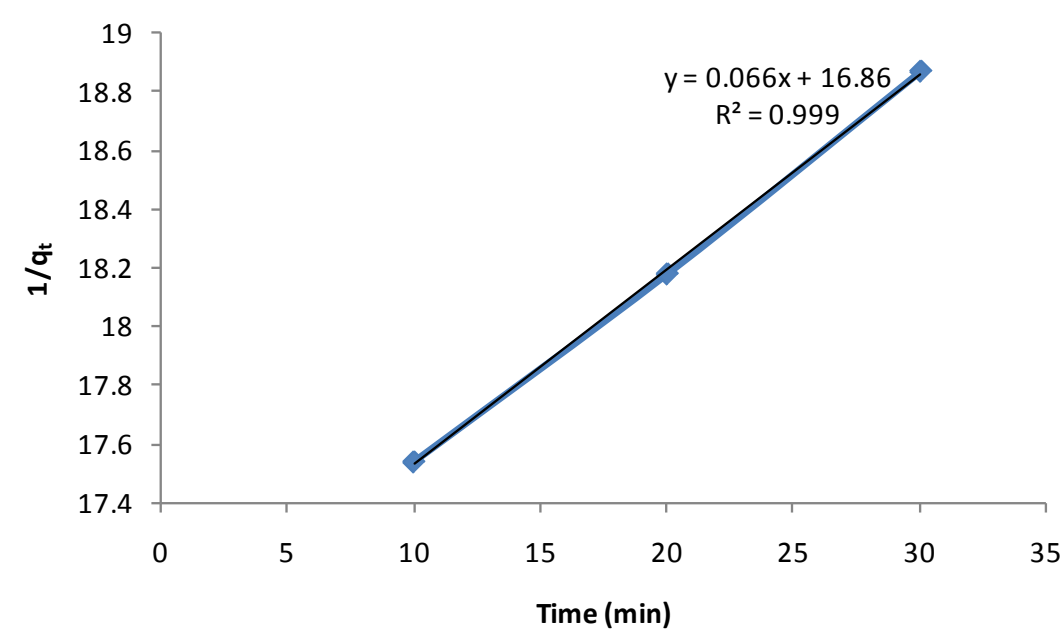

Figure 16. Plot of $1 / q_{t}$ vs. $t$ for the adsorption of Congo Red onto layered double hydroxide. 


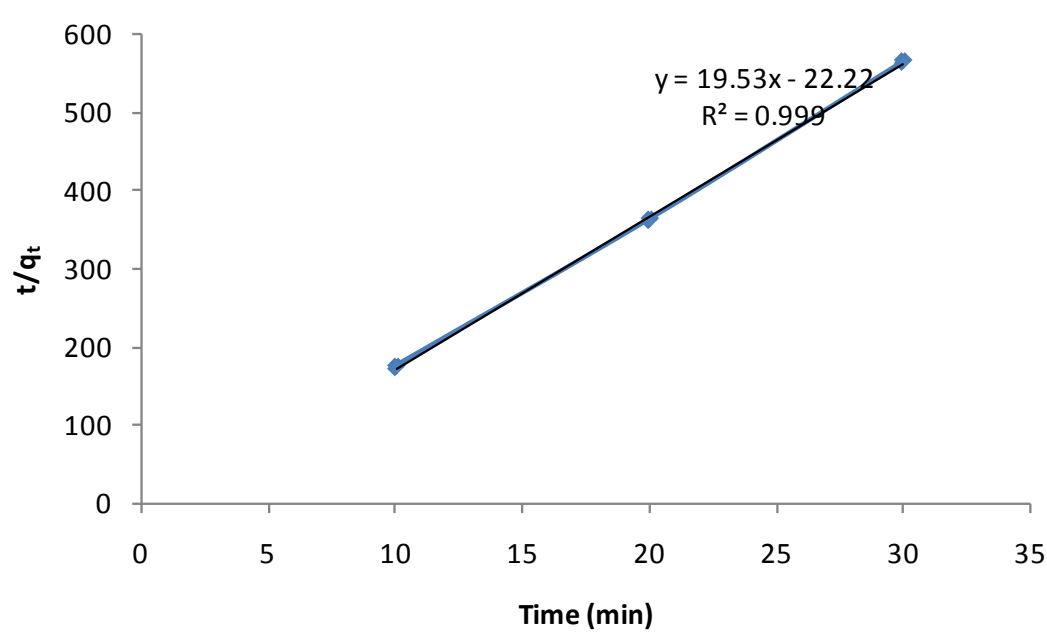

Figure 17. Plot of $1 / q_{t}$ vs. $t$ for the adsorption of Congo Red onto layered double hydroxide.

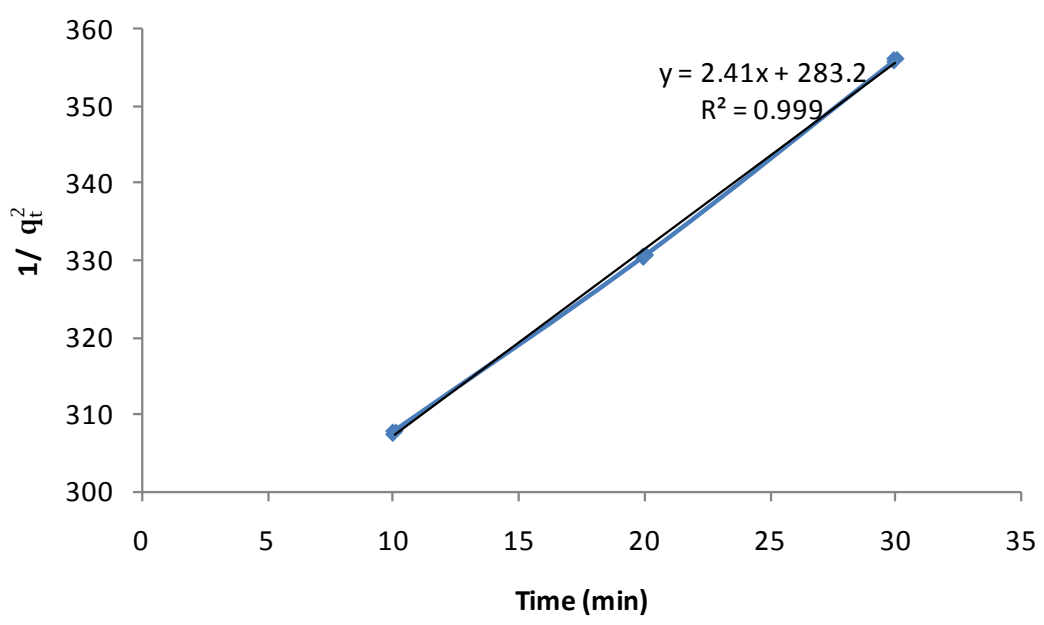

Figure 18. Plot of $1 / q_{t}^{2}$ vs. $t$ for the adsorption of Congo Red onto layered double hydroxide.

Congo Red dye in aqueous solution. The experimental data were best defined by Temkin isotherm $\left(R^{2}=1\right)$ and zero-order kinetic model $\left(R^{2}=1\right)$. The values of $\Delta H^{o}$ and $\Delta S^{o}$ indicated that the adsorption process was endothermic and process was dependent on increase in temperature, thereby increasing the randomness of the solid/ liquid phase of the reaction system.

\section{References}

[1] Gupta, V.K., Mittal, A., Krishnan, L. and Gajbe, V. (2004) Adsorption Kinetics and Column Operations for the Removal and Recovery of Malachite Green from Wastewater Using Bottom Ash. Separation and Purification Technology, 40, 87-96. http://dx.doi.org/10.1016/j.seppur.2004.01.008

[2] Singh, K. and Arora, S. (2011) Removal of Synthetic Textile Dyes from Wastewater: A Critical Review on Present Treatment Technologies. Critical Reviews in Environmental Science and Technology, 41, 807-878. http://dx.doi.org/10.1080/10643380903218376

[3] Anjaneyulu, Y., Chary, N.S. and Raj, D.S.S. (2005) Decolourization of Industrial Effluents-Available Methods and Emerging Technologies. Reviews in Environmental Science and Biotechnology, 4, 245-273. http://dx.doi.org/10.1007/s11157-005-1246-z

[4] Prasad, A.L. and Santhi, T. (2012) Adsorption of Hazardous Cationic Dyes from Aqueous Solution onto Acacia nilotica Leaves as an Eco Friendly Adsorbent. Sustainable Environment Research, 22, 113-122. 
[5] Gupta, V.K., Pathania, D., Singh, P., Kumar, A. and Rathore, B.S. (2014) Adsorptional Removal of Methylene Blue by Guar Gum-Cerium (IV) Tungstate Hybrid Cationic Exchanger. Carbohydrate Polymers, 101, 684-691. http://dx.doi.org/10.1016/j.carbpol.2013.09.092

[6] Ghaedi, M., Hassanzadeh, A. and Nasiri Kokhdan, S. (2011) Multiwalled Carbon Nanotubes as Adsorbents for the Kinetic and Equilibrium Study of the Removal of Alizarin Red S and Morin. Journal of Chemical and Engineering, 56, 2511-2520.

[7] Yao, Z., Wang, L. and Qi, J. (2009) Biosorption of Methylene Blue from Aqueous Solution Using a Bioenergy Forest Waste: Xanthocerassorbifolia Seed Coat. Clean, 37, 642-648.

[8] Abd Ei-Latif, M.M., Ibrahim, A.M. and EI-Kady, M.F. (2010) Adsorption Equilibrium, Kinetics and Thermodynamics of Methylene Blue from Aqueous Solutions Using Biopolymer Oak Sawdust Composite. Journal of American Science, 6, 267-283.

[9] Vimonses, V., Lei, S., Jin, B., Chow, C.W.K. and Saint, C. (2009) Kinetic Study and Equilibrium Isotherm Analysis of Congo Red Adsorption by Clay Materials. Chemical Engineering Journal, 148, 354-364. http://dx.doi.org/10.1016/j.cej.2008.09.009

[10] Sen, T.K., Afroze, S. and Ang, H.M. (2011) Equilibrium, Kinetics and Mechanism of Removal of Methylene Blue from Aqueous Solution by Adsorption onto Pine Cone Biomass of Pinus Radiate. Water, Air, Soil Pollution, 218, 499515. http://dx.doi.org/10.1007/s11270-010-0663-y

[11] Zenasni, M.A., Meroufel, B., Amrouche, A., Naâr, F., Merzouka, F. and Difallah, F. (2012) Phytoremédiation de Zn (II) par les racines de Calotropis Procera (Bechar, Algérie). ScienceLib, 4, 1-15.

[12] Dawood, S. and Kanti Sen, T. (2012) Removal of Anionic Dye Congo Red from Aqueous Solution by Raw Pine and Acid-Treated Pine Cone Powder as Adsorbent: Equilibrium, Thermodynamic, Kinetics, Mechanism and Process Design. Water Research, 46, 1933-1946. http://dx.doi.org/10.1016/j.watres.2012.01.009

[13] Zenasni, M.A., Benfarhi, S., Mansri, A., Benmehdi, H., Meroufel, B., Desbrieres, J. and Dedriveres, R. (2011) Influence of $\mathrm{pH}$ on the Uptake of Toluene from Water by the Composite Poly(4-vinylpyridinium)-Maghnite. African Journal of Pure and Applied Chemistry, 5, 486-493.

[14] Hsu, L.C., Wang, S.L., Tzou, Y.M., Lin, C.F. and Chen, J.H. (2007) The Removal and Recovery of Cr(VI) by Li/Al Layered Double Hydroxide (LDH). Journal of Hazardous Materials, 142, 242-249. http://dx.doi.org/10.1016/j.jhazmat.2006.08.024

[15] Hu, Q.H., Xu, Z.P., Qiao, S.Z., Haghseresht, F., Wilson, M., Lu, G.Q., et al. (2007) A Novel Color Removal Adsorbent from Heterocoagulation of Cationic and Anionic Clays. Journal of Colloid and Interface Science, 308, 191-199. http://dx.doi.org/10.1016/j.jcis.2006.12.052

[16] Roto, R., Nindiyasari, F. and Tahir, I. (2009) Removal of Hexacyanoferrate (II) Using Zn-Al-OA Hydrotalcite as an Anion Exchanger. Journal of Physical Science, 20, 73-84.

[17] Iyi, N., Ebina, Y. and Sasaki, T. (2011) Synthesis and Characterization of Water-Swellable LDH (Layered Double Hydroxide) Hybrids Containing Sulfonate-Type Intercalant. Journal of Materials Chemistry, 21, 8085-8095. http://dx.doi.org/10.1039/c1jm10733j

[18] Ayawei, N., Ekubo, A.T., Wankasi, D. and Dikio, E.D. (2015) Synthesis and Application of Layered Double Hydroxide for the Removal of Copper in Wastewater. International Journal of Chemistry, 7, 122-132.

[19] Ayawei, N., Ekubo, A.T., Wankasi, D. and Dikio, E.D. (2015) Equilibrium, Thermodynamic and Kinetic Studies of the Adsorption of Lead (II) on Ni/Fe Layered Double Hydroxide. Asian Journal of Applied Sciences, 3, 207-217.

[20] Vadi, M. and Rahimi, M. (2014) Langmuir, Freundlich and Temkin Adsorption Isotherms of Propranolol on Multi-Wall Carbon Nanotube. Journal of Modern Drug Discovery and Drug Delivery Research, V1I3.

[21] Yasin, Y., Malek, A.H.A. and Sumari, S.M. (2010) Adsorption of Eriochrome Black Dye from Aqueous Solution onto Anionic Layered Double Hydroxides. Oriental Journal of Chemistry, 26, 1293-1298.

[22] Badreddine, M., Legrouri, A., Barroug, A., De Roy, A. and Besse, J.P. (1999) Ion Exchange of Different Phosphate Ions into the Zinc-Aluminium-Chloride Layered Double Hydroxide. Materials Letters, 38, 391-395. http://dx.doi.org/10.1016/S0167-577X(98)00195-5

[23] Arivoli, S., Venkatraman, B.R., Rajachandrasekar, T. and Hema, M. (2007) Adsorption of Ferrous Ion from Aqueous Solution by Low Cost Activated Carbon Obtained from Natural Plant Material. Research Journal of Chemistry and Environment, 17, 70-78.

[24] Dawodu, F.A., Akpomie, G.K. and Ogbu, I.C. (2012) Isotherm Modeling on the Equilibrium Sorption of Cadmium (II) from Solution by Agbani Clay. International Journal of Multidisciplinary Sciences and Engineering, 3, 9-14.

[25] Choy, K.K.H., Mckay, G. and Porter, J.F. (1999) Sorption of Acidic Dyes from Effluents Using Activated Carbons. Resources, Conservation and Recycling, 27, 57-71. http://dx.doi.org/10.1016/S0921-3449(98)00085-8 
[26] Flavio, A.P., Silvio, L.P.D., Ede, C.L. and Edilson, V.B. (2008) Removal of Congo Red from Aqueous Solution by Anilinepropylsilica Xerogel. Dyes and Pigments, 76, 64-69. http://dx.doi.org/10.1016/j.dyepig.2006.08.027

[27] Ahmet, G. (2009) Synthesis and Characterization of Hybrid Congo Red from Chloro-Functionalized Silsesquioxanes. Turkish Journal of Chemistry, 34, 437-445.

[28] Bulut, Y. and Aidin, H. (2006) A Kinetic and Thermodynamics Study of Methylene Blue Adsorption on Wheat Shells. Desalination, 194, 259-267. http://dx.doi.org/10.1016/j.desal.2005.10.032

[29] Ayawei, N., Ekubo, A.T., Wankasi, D. and Dikio, E.D. (2015) Mg/Fe Layered Double Hydroxide for Removal of Lead (Ii): Thermodynamic, Equilibrium and Kinetic Studies. European Journal of Science and Engineering, 3, 1-17.

[30] Ayawei, N., Ekubo, A.T., Wankasi, D. and Dikio, E.D. (2015) Adsorption Dynamics of Copper Adsorption by Zn/ $\mathrm{Al}-\mathrm{CO}_{3}$. IJACSA, 3, 57-64. 